Адрес статьи / To link this article: http://cat.ifmo.ru/ru/2018/v3-i1/126

\title{
Цифровой этикет: вопросы методологии
}

\author{
Р.И. Мамина
}

Санкт-Петербургский государственный электротехнический университет «ЛЭТИ», Россия

maminaraisa@yandex.ru

\begin{abstract}
Аннотация. Показано, что цифровой этикет - это новый вид этикетной коммуникации, который формируется в пространстве Всемирной Глобальной паутины третьего поколения Web 3.0, и, как следствие, функционирует как в онлайн, так и в оффлайн/онлайн режимах. Рассмотрены роль и значение цифрового этикета в условиях современных реалий, выделены основные направления его развития - это непосредственное общение в сети, взаимодействие с гаджетами, а также самопрезентации в сети. Специфика и особенности каждого направления рассмотрены в рамках цифрового этикета, как единой целостной системы. Подчеркивается, что новый вид этикета представляет собой современное междисциплинарное знание теоретикоприкладного характера, которое находится в стадии своего становления, поэтому с необходимостью требует внимания специалистов, представляющих как гуманитарное знание, так и знание новых и новейших информационно-коммуникативных технологий.
\end{abstract}

Ключевые слова: информационное общество, сетевой этикет, цифровой этикет, семантический Web 3.0, номофобия, FOMO-фобия, фаббинг, цифровой детокс, цифровая самопрезентация, SIP-телефония, деловые переговоры, конференц-колл.

\section{Введение}

В эпоху цифровых технологий этикетная коммуникация приобретает характер одного из достаточно значимых направлений коммуникативного взаимодействия в сети, актуальность которого постоянно возрастает вместе с ускоренными темпами развития новых и новейших информационно-коммуникативных технологий (ИКТ) и постоянно увеличивающимся ростом числа пользователей этих технологий.

Однако тема цифрового этикета представлена и широко обсуждается не только на уровне пользователей и специалистов, занимающихся этикетной проблематикой, сегодня цифровой этикет стал предметом особого внимания и современных медиа, в частности, таких как интернетиздание «Медуза», новое онлайн-издание «ЧТД», журнал «Сноб», имеющий печатную и электронную версии и другие, отдельно следует выделить Телеграмм-канал «Цифровой этикет», который непосредственно ориентирован на исследование специфики цифрового этикета. В свою очередь, актуализация цифровой экономики, как мировая тенденция, актуализирует значение цифрового этикета и для субъектов делового сообщества современного глобального рынка, а также для представителей официальных кругов современного глобального мира. Поэтому цифровой этикет, определяющий правила поведенческой культуры в сети в новых условиях и их специфику на межличностном, групповом и представительском уровнях взаимодействия, — это 
один из вызовов новой информационной реальности, который требует своего ответа, при этом, в первую очередь, речь идет о приобретения цифровым этикетом своего статус-кво. В этой связи с необходимостью встает вопрос о методологических основаниях, на которых строится вся архитектура цифрового этикета, обратимся к этим основаниям.

\section{1. Современный этикет и его виды}

Развитие современной информационной цивилизации сопровождается формированием нового коммуникативного пространства, которое развивается не только в реальном, но и виртуальном измерениях. Соответственно, обращение к этикетной тематике в новых условиях предполагает последовательное рассмотрение этикетной коммуникации в реальном и виртуальном измерениях. В реальном бытии современного социума этикет представлен всеми существующими видами этикетной коммуникации, в виртуальном - сетевым этикетом и цифровым этикетом. Однако, цифровой этикет - это один из новых феноменов новой информационной реальности, в настоящее время он находится на этапе своего становления и развития, поэтому еще мало изучен и как понятие, и как явление. Главная сложность заключается в том, что при исследовании цифрового этикета важно исходить из его двойной природы - этикетной, обусловленной исторически сложившейся культурной нормой, а также технологической, обусловленной развитием новых и новейших ИКТ. Обратимся, в первую очередь, к этикетной природе нового коммуникативного феномена новой информационной эпохи, определение этой природы начинается с определения понятия «этикет».

\section{1. Понятие «этикет»}

Термин «этикет» имеет французское происхождение, в переводе «etiguette» означает манеру поведения. Однако тема этикета многопланова и само содержание термина «этикет» многозначно и может быть сужено или расширено в зависимости от того, что выделяется в качестве объекта рассмотрения: конкретный, индивидуальный для определенного круга людей, набор внешне проявляющихся форм поведения и общения, или вся совокупность норм и правил поведения, принятых в социуме, об этикете принято говорить в узком или широком значении этого слова. В то же время, независимо от того, идет ли речь об этикете в узком или широком значении, исследователи, занимающиеся данной проблематикой с позиций различных областей гуманитарного знания, рассматривают этикет как сложное социокультурное явление, поскольку этикет, помимо внешне проявляемых форм поведения и общения, имеет глубокое смысловое и нравственное содержание.

Этикет, рассматриваемый только со стороны формы, теряет свою мотивационную часть внутреннюю интенцию поведения, а это значит, что независимо от того, насколько красиво обставлена ситуация, решающее значение для этикетной коммуникации имеет ее нравственное содержание. Но информацию об этом содержании мы получаем на основании формы, т. е. внешней поведенческой культуры, которая выражается как прямо через наличие этикетного знака, так и косвенно через невербальный язык общения, который включает в себя кинетические, проксемические и паравербальные характеристики, отсюда взаимозависимость и взаимообусловленность содержания и формы в этикетной коммуникации. Поэтому употребление таких словосочетаний как «манеры поведения», «правила красивого поведения», «правила вежливости», «правила хорошего тона» и т.п., хотя и является условно правильным, но в них не учитывается внутреннее содержание этикетных норм. В отличие от правил хорошего тона, где определяющим является форма самоподачи, этикетное поведение всегда ценностно-обусловлено, всегда направлено на признание ценности личности каждого отдельно взятого человека, необходимости уважения его чести, достоинства и положения в обществе, выражаемое через реальное поведение партнеров по общению.

Общесоциологическую значимость этикета раскрывает исторический процесс его формирования и развития. Этикет, как нормативно-этическая система стабилизирующего значения, имеет глубокие исторические корни и ведет свое происхождение из архаических праценностей, где наряду с ритуалами, мифами и легендами, традициями и обрядами, выполнял функцию охраны целостности рода и регулировал отношения как внутри рода, так и между родами, поэтому выступал как ценностный регулятор внутригрупповых и межгрупповых

International Culture \& Technology Studies, Vol. 3, No. 1-2 
отношений. Вместе с разложением первобытного общества происходит постепенный распад синкретического «Мы-сознания» и выделение «Я-сознания», в этих условиях этикет постепенно оформляется в относительно самостоятельную ценностно-обусловленную форму культуры, регулирующую уже не только внутригрупповые, межгрупповые, но и межличностные отношения [6].

Однако в антагонистическом обществе этикет всегда носил ярко выраженный классовый характер, и вплоть до начала XX столетия представлял собой кодекс правил красивого поведения светской публики европейских монарших режимов. Вместе с демократизацией общества, этикет возвращает исторически сложившуюся миссию нормативно-ценностного регулятора отношений, которые складываются между людьми в процессе их жизнедеятельности. При этом, в первую очередь, речь идет о защитной функции, которая, как подчеркивают специалисты-этнографы, была весьма приметной для традиционной культуры и выражалась в нацеленности этикета на психическое здоровье и отдельной личности, и всего социума [13].

В настоящих условиях этикет представляет собой нормативно-ценностный стабилизатор всех видов взаимоотношений, которые складываются в современном обществе на межличностном, групповом и представительском уровнях, и выступает как особая система защиты прав и свобод личности на уровне культурной нормы, как специфическая охранная система моральнопсихологического значения, выработанная в ходе исторического и культурного процессов общественного развития. И хотя, в современной инновационной, личностно-креативной культуре соотношение ценностного и нормативного механизмов управления поведением членов общества существенно изменилось в сторону преобладания ценностного, и одна из особенностей личностного роста состоит в саморегуляции поведения, тем не менее, как подчеркивают специалисты, «определенным нормам должна подчиняться самая духовно независимая личность - без этого невозможна совместная жизнь людей, требующая, чтобы свобода каждого была ограничена свободой других, в противном случае поведение человека становится асоциальным хулиганским, преступным, как минимум эпатажным, и свобода вырождается в произвол» $[3$, c.166].

Поэтому этикет - это не просто правила вежливости, или правила красивого поведения, это исторически сложившаяся нормативно-этическая многоуровневая система регуляции отношений в социуме, это феномен культуры, где в системе ценностных установлений, главной ценностью является сам человек и его отношение к Другому / Другим.

\section{2. Этикет в информационном обществе: функционально-видовой аспект}

В современном информационном обществе, как уже отмечалось, этикет существует в двух основных измерениях: в реальном и виртуальном. В пространстве реального времени этикет представлен следующими основными видами: придворный или королевский этикет, воинский, дипломатический, общегражданский, деловой этикет и этноэтикет, а также их подвидами в рамках каждого вида, например, в рамках делового этикета - административный, служебный этикет и корпоративный этикет, и др. В зависимости от конкретного вида проявляется специфика всех функций этикета: аксиологической, регулятивной, оценочной, коммуникативной, защитной и культурно-воспитательной [5]. Остановимся подробнее на основных функциональных характеристиках этикета.

В частности, нормативно-этическая сущность этикета закладывает основную функцию этикета — регулятивную, причем в первую очередь речь идет о нормировании ролевых отношений на межличностном, групповом и представительском уровнях. Фиксация социальных ролей и соответствующая им заданность программы поведения ведет к упорядочиванию социальных связей и отношений, определяет их общую направленность. Соблюдение правил этикета и, прежде всего, заложенных в них норм ролевой регуляции является условием функционального развития социума, в то же время нарушение правил этикета дает импульс к постепенной дестабилизации существующих отношений, является свидетельством наступающего хаоса. В целом это означает, что регулятивная функция этикета является основополагающей функцией, поскольку этикет, подчеркнем еще раз, выступает, прежде всего, как нормативное комплексное образование стабилизирующего значения. 
Однако этикет - это исторически сложившаяся форма культуры, поэтому предопределяют этикетную норму и задают ее направленность нравственные ценности, как основополагающие регулирующие инстанции, отсюда детерминирующая роль аксиологической функции, которая проявляется в определяющем значении системы ценностных установок на характер общения. Основание этой системы составляют универсальные, общечеловеческие ценности, такие как почтительное отношение к старшим, к родителям, к женщине, к людям, занимающим более высокое социальное положение, правила гостеприимства, понятия справедливости, чести, достоинства, и др. В то же время иерархия ценностей, культивируемых и традиционно поддерживаемых в обществе, характеризует различие региональных и национальных культур. Например, проблема «Восток - Запад» имеет в своей основе разные ценностные доминанты. Восток сохраняет систему ценностей традиционного типа культуры с ее мифологической генетикой и ориентацией на коллективную ответственность, а Запад утверждает свободу личности и демократию как верховные ценности. Однако, наряду с общечеловеческими и национальными ценностями, система ценностных оснований с необходимостью включает в себя также конкретноисторические ценности больших социальных групп и ценности малых референтных групп, отсюда специфика аксиологической функции и ее значение для определения характера этикетной коммуникации.

Акт соотнесения реального поведения партнеров по общению с некоей идеальной нормой, зафиксированной в той или иной национальной культуре, или в деловой культуре современного глобального делового сообщества составляет содержание уже оценочной функции этикета. Относительное соответствие этой идеальной норме воспринимается не как формальная констатация выполнения нормы, а как проявление уважения к человеку и на индивидуальном, и на представительском уровнях. Поэтому оценочная функция проявляется как подтверждение собственной значимости через наблюдаемое, реальное поведение партнеров по общению в его соотнесенности с идеальной нормой, выраженное этикетными средствами, такая соотнесенность определяет характер и содержание эстетической функции этикета.

Эстетическая функция формирует правила «красивого поведения» и носит украшательский характер. При этом в качестве формы выступают как сам этикетный знак, так и вся дополнительная информация кинетического, проксемического и паравербального значения, то есть все, что касается языка невербального общения. Форма в этикете воплощает нравственное содержание и приобретает эстетическую ценность только как результат ее соответствия такому содержанию.

Однако за соответствие формы ее содержанию в этикетной регуляции отвечает коммуникативная функция, поскольку реализует ценностное содержание идеальной нормы, зафиксированной в этикете через совокупность конкретных поведенческих актов. В рамках этих актов определяются первые роли и степень дистанции, которые зависят от вида общения и конкретной ситуации - таково основное содержание коммуникативной функции. В практической плоскости это содержание реализуется посредством всех форм этикетной коммуникации: письменной, поведенческой и речевой.

Письменный, речевой и поведенческий этикет - это не виды этикета, а только формы выражения этикетной коммуникации. [6] Например, деловой этикет строится на принципах партнерства, а воинский этикет - на строгом соблюдении принципов субординации, при этом каждый вид характеризуется всеми тремя формами этикетной коммуникации: письменной, поведенческой и речевой, которые как по отдельности, так и в целом, реализуют на практике специфику каждого из этих видов на фоне общей направленности этикетных установлений на уважение к Другому / Другим. Такое уточнение является важным с точки зрения анализа функциональных и видовых характеристик этикета как регулятора стабилизирующего значения реальных общественных отношений.

В то же время, реализация всех перечисленных функций этикетной регуляции, включая защитную, как специфическую охранную систему морально-психологического значения, возможна только при условии целенаправленного формирования ценностного отношения и ценностных ориентаций индивида, поскольку они являются свойствами приобретенными, а не заданными человеку от рождения, отсюда роль и значение культурно-воспитательной функции этикета. В целом, все функции этикета взаимосвязаны и представляют собой единую ценностно-

International Culture \& Technology Studies, Vol. 3, No. 1-2 
детерминированную систему, определяющую нормативно-этическую сущность этикета и его ориентированность на гуманизацию отношений и формирование культуры поведения в обществе. Специфика всех функций этикета и всех форм этикетной коммуникации проявляется в зависимости от конкретного вида этикета, действующего в режиме реального времени.

В виртуальном пространстве этикетная составляющая современной коммуникации представлена сетевым этикетом и цифровым этикетом. Функционально они отражают сущность этикетной коммуникации в виртуальной реальности на разных этапах развития World Wide Web или Всемирной Глобальной паутины.

Сетевой этикет формируется на начальных этапах развития Web, поэтому определяет правила поведения в сети и правила ведения электронной переписки и, соответственно, включает в себя поведенческую и письменную формы этикетной коммуникации. Вместе с развитием Web 2.0 сетевой этикет приобретает новые качественные характеристики, обусловленные спецификой второго поколения Web и его возможностями, но в целом все еще рассматривается специалистами как свод определенных правил поведения в сети, имеющих в основном этическую направленность.

Цифровой этикет оформляется в вид этикетной коммуникации в пространстве нового, третьего поколения - Web 3.0 и, как следствие, реализует сущностные характеристики этикета в виртуальной среде, осуществляемые на базе новых и новейших ИКТ и формируется как нормативно-этический регулятор коммуникативного взаимодействия в сети при помощи всех форм этикетной коммуникации: письменной, поведенческой и речевой. В целом, цифровой этикет представляет собой более широкое и емкое понятие, чем сетевой этикет.

Каждый вид этикета независимо от своего измерения может быть предметом специального анализа, однако, в целом, все виды этикетной коммуникации, протекающие в реальном и виртуальном измерениях, а также при их взаимодействии, представляют собой единое этикетное пространство современного информационного общества. Остановимся отдельно на специфике цифрового этикета, как нового вида этикетной коммуникации, отвечающей потребностям нового времени, однако сначала немного об истории вопроса, которая начинается с сетевого этикета.

\section{3. Сетевой этикет или Нетикет как предтеча цифрового этикета}

Сетевой этикет или Нетикет - это правила хорошего тона в виртуальном пространстве. Термин «Нетикет» представляет собой неологизм, который произошел от слияния английского «network» - сеть и французского «etiguette» — этикет.

Как новый вид этикетной коммуникации сетевой этикет появляется, по свидетельству аналитиков, в середине 80-х гг. прошлого века в эхоконференциях компьютерной сети FidoNet (ФИДО). Многие правила сетевого этикета, которым и сегодня подчиняется общение в Интернете, появились уже в то время, но они носили очень ограниченный характер. Временной интервал 80-90 гг. прошлого столетия специалисты определяют как период доинтернетных сетей. В теории информации период доинтернетных сетей получил название «Web 0.0», или «лексический» и рассматривается аналитиками как первые попытки объединения ресурсов в глобальные информационные сети, так как в то время сервер мог выполнять только команды пользователя, а пользователь - только читать данные сервера, поэтому в середине 80-х правила сетикета или нетикета еще не носили глобальный характер, эра World Wide Web или Всемирной Глобальной паутины в этот исторический период еще не наступила.

World Wide Web - изобретение британского ученого Тима Бернерс-Ли и его коллеги Роберта Кайо, появившееся на свет как результат попытки создания ими надежного инструмента для обмена данных между учеными физиками, которое датируется 1989 г. Поэтому принято считать, что история Глобальной сети Интернет, как объединение компьютеров для совместного использования информационных ресурсов человека, начинается в 90-е годы прошлого столетия с поколения Всемирной паутины - Web 1.0, когда образовалась сетевая морфология, которая предоставила возможность пользователю, входя в сеть получать информацию из любого ресурса.

Именно тогда, в начале последнего десятилетия прошлого века стали развиваться электронные библиотеки и электронные каталоги, в тот же период, а именно, в 1994 г. появляется первая книга, посвященная правилам поведения в сети — «Netiquette», eе автор Вирджиния Ши. 
Программист по специальности, В. Ши, руководствуясь многолетним опытом работы в Силиконовой долине, разработала и предложила вниманию пользователей десять ключевых правил Нетикета. При этом, несмотря на особую специфику нового вида этикетной коммуникации, в целом эти правила совпадают с правилами письменной и поведенческой культуры, а также нормами неформальной и деловой переписки, действующими в реальном времени, т. е. требуют вежливости, внимания и тактичности по отношению к другим людям. Поэтому главные нормативно-этические установки Нетикета звучат следующим образом: ведите себя так, чтобы Вас было легко понять, уважайте своего собеседника, не создавайте проблем другим людям и не мешайте нормальному диалогу.

Однако в нулевые годы нового века, на смену Web 1.0 пришел Web 2.0, или так называемая синстаксическая паутина с ее возможностью диалога: «ресурс - пользователь», «клиент - сервер». В новых условиях контент стал генерироваться уже пользователями сайта, но модерироваться администрацией. Термин «Web 2.0», определяющий новые качественные характеристики сети, был предложен в 2005 г. Тимом О’Рейли, основателем американского медиахолдинга O'Reilly Media, и Дейлом Дагерти, вице президентом данного медиахолдинга, специализирующегося на издании научной и научно-технической литературы, а также предоставляющего образовательные услуги в режиме онлайн.

Интересно, что уже в 2007 г. Тим О’Рейли совместно с другим своим коллегой - Джимми Уэйлсом, известным всему цивилизованному миру, как основатель и разработчик свободной энциклопедии Wikipedia, объявили о создании кодекса поведения для блогеров - Blogger's Code of Conduct, в котором они сформулировали основные правила поведения в сети в новых условиях [4]. Аналитики отмечают, что семь правил, разработанных О'Рейли и Уэйлсом, во многом и повторяют правила Нетикета, и в целом являются их достойным продолжением и развитием. Основные различия обусловлены появлением блогосферы и новыми функциями Web 2.0 , поэтому новый кодекс в сети часто называют не только моральным Кодексом поведения блогеров, но и Netiquette 2.0.

С большим сожалением можно констатировать, что правила сетевого этикета и на сегодняшний день все еще не стали достоянием всех пользователей, а многие из них даже не задумываются о значении поведенческой культуры в сети, но время не стоит на месте. В настоящих условиях сетевой этикет становится уже только частью, только составляющей нового вида этикетной коммуникации - цифрового этикета, который функционирует в условиях нового Web 3.0 и отражает его специфику.

Новый Web отдает прерогативу генерации и модерации контента самим пользователям, массовое распространение получили межсерверные отношения, основанные на базе информационных процессов. Специалисты прогнозируют и будущий прагматический Web $4.0-$ предполагается, что он будет осуществлять взаимодействие участников сети с помощью нейроинтерфейсов (мозг - мозг, мозг - машина), но главная тема сегодняшнего дня - это новый Web 3.0, его специфика и возможности.

По определению автора концепции нового Web Джейсона Калаканиса, руководителя Netscape.com, Web 3.0 - это высококачественный контент и сервисы, создаваемые профессионалами на технологической платформе Web 2.0. Данное определение было опубликовано в личном блоге Калаканиса 10 марта 2007 г. [10]. Сегодня наиболее распространенной версией трактовки понятия Web 3.0 является идентификация его как семантической паутины - Semantic Web [9]. В семантической паутине основной акцент делается на работе с метаданными. В теории информации метаданные - это данные о данных, информация об информации, описание контента. Поэтому семантический Web, по оценке специалистов, - это некая сеть над Сетью, содержащая метаданные о ресурсах Всемирной паутины и существующая параллельно с ней. В условиях семантического Web субъекты, наделенные полномочиями имеют возможность не просто контролировать субъективную реальность, но и транслировать ее. Именно Web 3.0, по оценке аналитиков изменил парадигму «реального» индивида в виртуальной реальности, что породило новый достаточно широкий спектр инфоэтических проблем как в сети, так и в реальной жизни, поскольку, благодаря новым качествам, новый Web функционирует и в виртуальном пространстве, и основательно интегрирован в практики нашей повседневной жизни $[3$, c. 36]. В связи с этим в настоящее время речь идет уже не только о развитии новых и новейших

International Culture \& Technology Studies, Vol. 3, No. 1-2 
ИКТ, открывающих новые возможности для человека и общества в целом, сегодня основной акцент делается на вопросах взаимодействия пользователей с этими технологиями.

Таким образом, в условиях нового Web 3.0 функциональные, и, прежде всего, коммуникативные характеристики глобальной сети выходят на качественно новый уровень, важным отличием которого является взаимодействие пользователей с новыми технологиями, в этой связи актуализируется значение цифрового этикета, как нормативно-этического регулятора коммуникативного взаимодействия в условиях новой виртуальной реальности.

\section{2. Цифровой этикет и его составляющие: методологический анализ}

Цифровой этикет, в отличие от Netiquette 1.0 Вирджинии Ши и Netiquette 2.0. Тима О’Рейли, это уже не просто свод определенных правил поведения в сети, имеющих в основном этическую направленность - это более объемное и сложное понятие. Новый этикет развивается в рамках Web 3.0. и с необходимостью, отражая специфику нового Web, представляет собой реализацию сущностных характеристик этикетной коммуникации в виртуальном пространстве цифровой среды, осуществляемых на базе новых и новейших ИКТ, отсюда не только этикетная, но и технологическая природа цифрового этикета. В то же время, несмотря на двойную природу нового этикета, по аналогии с Netiquette 1.0. и Netiquette 2.0., которые, подчеркнем еще раз, отражали специфику этикетной коммуникации в пространстве Web 1.0 и Web 2.0, цифровой этикет можно рассматривать как Netiquette третьего поколения. В цифровом этикете ценность Другого / Других не теряет своего значения, но имеет как прямой, так и опосредованный характер, обусловленный в том числе, знаниями и умениями пользователей взаимодействовать с новыми ИКТ, поэтому Netiquette, но уже - 3.0. В целом, цифровой этикет, формируясь на стыке гуманитарного и технико-технологического знаний, выступает как современное междисциплинарное знание, которое находится в стадии своего оформления. Однако на сегодняшний день уже возможно выделить следующие составляющие или направления его развития: первое - это общение в сети; второе - это практики взаимодействия пользователей с гаджетами и третье - это самопрезентации в сети.

Bсе три направления имеют свои особенности, инфоэтическую проблематику и, с необходимостью - этикетное решение. В то же время, следует еще раз особо подчеркнуть, что на сегодняшний день можно говорить только о становлении цифрового этикета, как нового вида этикетной коммуникации в виртуальной среде, методологическая база которого еще мало разработана, поэтому некоторые правила уже получили свое оформление, некоторые находятся в стадии обсуждения на уровне пользователей, новых СМИ и, соответственно, специалистов, в ряде случаев проблема существует, но еще не озвучена на уровне общественного запроса, а значит, нет и ее решения. Остановимся на некоторых советах цифрового этикета или Netiquette 3.0 в рамках всех трех указанных направлений, уже получивших свое оформление, и в первую очередь, обратимся к культуре общения в сети.

\section{1. Цифровой этикет: общение в сети}

В условиях цифровых реалий общение в сети включает в себя: непосредственное общение в сети, пользование электронной почтой и мессенджеры. Все составляющие отражают специфику новых и новейших ИКТ и широко обсуждаются не только в кругу самих пользователей, но и в современных медиа, а также специалистов, занимающихся этикетной тематикой. Среди наиболее часто встречающихся тем для обсуждения - это нарушение личных границ в социальных сетях, приватность личной переписки, вопросы грамотности в сети, вопросы безопасности, включая корпоративную безопасность, кибербезопасность, авторское право и др. Не остаются без внимания и такие, казалось бы, менее значимые, но не менее важные вопросы для обсуждения, как тяжелые файлы, наличие названия темы в электронном письме, тема приветствия и заключительная формула вежливости в конце письма, использование эмодзи в электронной переписке, обратная связь и другие вопросы, касающиеся виртуального бытия в сети, и их проблематики.

Однако, в ряде случаев определенные правила на обозначенные проблемы уже определены. Например, проблема тяжелых файлов, которые часто отправляют по почте, прикрепляя их прямо к письму, заключается в том, что такие файлы не только съедают все место в почтовом ящике, но и заставляют потратить получателя свой трафик (у кого-то он ограничен),

Культура и технологии, Том 3, № 1-2 
отсюда появившаяся как в среде пользователей, так и на уровне специалистов рекомендация: загружайте тяжелые файлы в файлообменник и передавайте ссылку [5]. Именно такое поведение в сети будет считаться этикетным поскольку оно направлено на уважительное отношение к адресату и экономит его трафик и деньги.

В то же время существует целый ряд вопросов, на которые пока нет однозначных ответов, например, «в каких случаях можно использовать чат социальных сетей для решения деловых вопросов»; «когда и каким способом можно напомнить о себе адресату, если он не ответил на письмо»; «удобно ли добавлять в друзья в социальных сетях человека, с которым едва знаком», «в каких случая допустимо использовать эмодзи, чтобы построить эмоционально-эффективную коммуникацию, в каких не допустимо» и другие. В настоящее время на эти и другие подобные вопросы ответы в рамках этикетной коммуникации пока еще не сформулированы. Поэтому при сетевом общении, по мнению большинства пользователей, следует руководствоваться, прежде всего, здравым смыслом. А вот как звучат на такие случаи советы Телеграмм-канала «Цифровой этикет»: «Самый простой способ освоить цифровой этикет - все время задавать себе вопросы:

- не доставляю ли я кому-либо неудобство;

- не подвергаю ли я кого-нибудь опасности;

- не отнимаю ли я чье-то время, внимание (и трафик!)» [5].

Эти достаточно простые советы достаточно точно отражают главную этикетную установку поведенческой культуры в практиках реального и сетевого общения - Другой / Другие как ценность.

Отдельно среди наиболее обсуждаемых тем следует выделить вопросы, касающиеся грамотности в сети. В последнее время в Интернете сложился определенный сетевой сленг, когда слова сознательно пишутся с ошибками, но воспринимаются как верно написанные, однако злоупотреблять этим не следует. Специалисты подчеркивают, что цифровая эпоха - это эпоха письменной коммуникации, отсюда и то значение, которое придают сегодня грамотности в сетях, тем более, что в настоящих условиях существует достаточно много программ и ресурсов, которые помогают проверять ошибки. Поскольку, например, в деловой сфере культура письма - это просто отдельная тема, напрямую связанная с деловой репутацией компании и ее бренд-имиджем; при групповом общении в сетях, как правило, обозначены определенные нормы, исполнение которых контролируется модератором, а неподчинение им имеет свои последствия, вплоть до удаления из группы, в свою очередь, на уровне межличностного общения не все и не всегда положительно относятся к нарочитой небрежности к правилам орфографии и пунктуации в сети.

В настоящих условиях грамотность в сети приравнивается к правилам вежливости в реальной жизни и, несмотря на различные дискуссии на эту тему и попытки оправдать грамматические ошибки в пользу самого сообщения, скоростного режима интернеткоммуникации, или, например, в пользу свободы от любых ограничений в сети, или другими причинами, все больше пользователей высказываются за обязательную грамотность в сети, что можно расценивать как наметившуюся тенденцию, направленную на формирование правил цифрового эпистолярного, или письменного этикета, где установка на Другого / Других является определяющей.

Однако подчеркнем еще раз, сегодня поведение в сети, в первую очередь, обусловлено не просто развитием новых технологий, а умением взаимодействовать с этими новыми технологиями, поэтому, в первую очередь, речь идет об анализе ситуаций, напрямую связанных с их функциональными характеристиками, и поведенческом решении возникающих ситуаций. В частности, остановимся на такой технологической функции как кросспостинг и поведенческой культуре в сети, связанной с особенностью этой функции.

Кросспостинг - это автоматическое или полуавтоматическая массовая публикация постов с основного блога на другие блоги и блог-серверы [15]. В частности, когда личные снимки могут из одной социальной сети появиться в другой. С одной стороны это удобно и расширяет аудиторию, которая видит сообщение, с другой, как советуют специалисты, лучше не связывать свои аккаунты, чтобы не было ненужных повторов.

International Culture \& Technology Studies, Vol. 3, No. 1-2 
В качестве примера можно привести и другие технологические особенности цифровой среды и их этикетное решение. Например, в современной деловой коммуникации широко обсуждаются ситуации, когда сотрудники известных компаний одним репостом записи отражали лишь собственное мнение, но это мнение вызывало множество вопросов к самой компании. В таких случаях сотрудники часто указывают, что их сообщение имело личный, а не официальный характер, это так называемый дисклеймер - письменный отказ от ответственности за возможные последствия в результате действий человека (или организации), заявившего данный отказ. Аналитики подчеркивают, что на деле, если социальная сеть использовалась и прежде в профессиональных целях, дисклеймер никак не спасает сотрудника от ассоциации с работодателем, не защищает дисклеймер и от увольнения, или другого наказания со стороны работодателя, а самого работодателя от внешних претензий. За корпоративными брендами организации, как и за персональными брендами самих сотрудников в социальных сетях достаточно пристально наблюдает «третий глаз» с разными целями, в том числе и, для того, чтобы узнать самую новую информацию о деятельности компании, ее отношении к последним новостям, а также реакцию на эти новости как в лице руководства, так и сотрудников компании и т.д.

Поэтому, когда одна и та же сеть служит для рабочих и личных целей, одним из решений проблемы, по мнению специалистов, может быть регистрация соответствующего «альтер-эго», в виде различных аккаунтов, чтобы исключить возможные недоразумения и возможные комментарии. Такая практика становится все более распространенной: например, на первой странице, как советуют специалисты, вы делаете заявление от имени компании, распространяете новости о вашей сфере деятельности, ведете деловую переписку и т. п., второй профиль - это ваша личная жизнь, фотографии, общение с друзьями, публикация различных заметок, которые отражают вашу личную позицию, поэтому не могут быть оценены с позиций деятельности компании. Предлагаются также и другие варианты решения данной проблемы этикетным способом, например, если вы не хотите создавать два аккаунта, можно настроить собственные настройки приватности, чтобы личная информация была доступна только самым близким людям [16]. Принцип уважения к приватности информации, на котором всегда строилась этикетная коммуникация, в условиях цифровых реалий не только не теряет своей актуальности, но и значительно возрастает.

Таковы некоторые советы специалистов, связанные с поведенческой культурой в сети, которые уже сформировались как правила цифрового этикета. При этом, говоря о цифровом этикете, мы говорим не о нормах, имеющих регламентированный характер, а о советах и рекомендациях, касающихся поведенческой культуры в сетях. В основе такой терминологической особенности, подчеркнем еще раз, двойная природа цифрового этикета, поскольку он представляет собой реализацию сущностных характеристик этикетной коммуникации в виртуальном пространстве, осуществляемых на базе новых и новейших ИКТ. Анализ ситуаций, связанных с использованием технологических инструментов, позволяет специалистам давать необходимые рекомендации, направленные на формирования цифровой культуры в виртуальном пространстве. В этой связи отдельно следует остановиться на рекомендациях, посвященных поведению в сети в новых условиях, предлагаемые нашими украинскими коллегами Александром Элькиным и Марией Пащенко, создателей проекта «НеоЭтикет: новая грамотность в цифровом веке».

Авторы концепции вводят понятие «Неоэтикет» и объясняют его как неологизм, который означает современный этикет, что, собственно, является синонимом цифровому этикету. В рамках проекта работает вебинар и выпущены две книги: «НеоЭтикет: новая грамотность в цифровом веке: Лучшие советы по социальным сетям для вашей карьеры» и «НеоЭтикет: новая грамотность в цифровом веке. Лучшие советы по электронной почте для вашей карьеры».

Все предлагаемые рекомендации, по свидетельству самих авторов, основаны на результатах международных независимых исследований и мнениях экспертов в области медиа, а также подкреплены их собственным опытом работы в сфере инновационных технологий, который они приобрели за рубежом и в Украине. Последовательный анализ ситуаций, связанных с использованием электронной почты и других технологических инструментов позволяет разработчикам проекта предлагать варианты этикетного решения выхода из сложных ситуаций. Особую ценность эти рекомендации представляют собой и потому, что создатели концепции формируют правила нового этикета, основываясь на маркетиноговом поиске наиболее часто

Культура и технологии, Том 3, № 1-2 
встречающихся ошибок в сети при активном участии непосредственно самих пользователей, объявляя, в том числе, и различные конкурсы на самые худшие ошибки. Авторы проекта подчеркивают, что в команде «человек - машина», активная позиция остается за человеком, поэтому человек должен научиться дружить с технологиями, чтобы достойно встретить будущее, и именно Неоэтикет, по их мнению, — это способ интегрироваться в будущее [14].

\section{2. Цифровой этикет: взаимодействие пользователей с гаджетами}

Важным продолжением темы этикетной коммуникации в условиях новых информационных реалий является направление, связанное с пользованием гаджетами. По оценке аналитиков данная проблематика находится сегодня в серой зоне, поскольку нормы, ограничивающие спонтанные поведенческие практики пользования гаджетами в условиях повседневности все еще не выработаны, а проблемы связанные с интернет-зависимостью, а также различного рода фобиями, детерминированными развитием ИКТ стоят достаточно остро. Остановимся несколько подробнее на некоторых явлениях зависимости от гаджетов, таких как номофобия, FОМО-фобия и фаббинг.

Номофобия (англ. Nomophobia от no mobile-phone phobia) - страх, фобия остаться без мобильного телефона или вдалеке от него. Люди, склонные к номофобии, как правило, даже идя по улице, постоянно пишут смс, проверяют сообщения, продолжают бесконечно общаться по телефону с кем-то из друзей. Главная причина, по оценке специалистов, это боязнь оказаться беспомощным, т.е. как бы изолированным от привычного мира. Номофобия - это молодая болезнь, принято считать, что она возникла вместе с появлением в 2007 г. смартфона или «умного телефона», в котором были заложены возможности стационарного компьютера. Люди быстро привыкли к подобному комфорту, но, к сожалению, некоторые стали рабами своих игрушек. Человек, зараженный номофобией, практически перестает общаться с окружающими его людьми, виртуальное общение становится предпочтительнее, чем живое, все свободное время уходит на прослушивание мелодий, скачивание картинок, игр, смену настроек и т.п.

FOMO - аббревиатура, образованная от английского словосочетания fear of missing out, что дословно означает пропустить что-то новое в сети. Впервые о синдроме FOMO, как о коварном «недуге», поработившим сознание современников, заговорили в 2011 г. Открытие этого синдрома принадлежит американскому сайту Urban dictionary, который собирает наиболее популярные в английском языке сленговые неологизмы. FOMO определяют, как постоянную боязнь пропустить важное событие, как навязчивое желание быть всегда в курсе того, что делают друзья, знакомые, близкие, это касается также работы, развлекательных мероприятий, и просто важных новостей и событий, происходящих в мире. Специалисты считают FOMO явлением, появившимся исключительно благодаря социальным сетям [12].

Фаббинг - еще одно из проявлений зависимости от гаджетов и сети. Когда вы общаетесь лично и при этом с кем-то постоянно переписываетесь, листаете паблики в социальных сетях, или звоните телефону, то, по сути, игнорируете своего собеседника, отсюда название - фаббинг phone (телефон) и snabbing (относиться с пренебрежением). Фаббинг - игнорирование присутствия другого / других в пользу гаджета, громкий разговор по телефону в общественных местах, бесконечные селфи и т.п. Как явление фаббинг, по мнению аналитиков, также как и номофобия, возникает в 2007 г. вместе с появлением смартфона или «умного телефона», Однако сам термин появляется в 2012 г. с легкой руки одного из сотрудников рекламного агентства McCann в процессе целенаправленного поиска названия для этого негативного явления.

Первыми забили тревогу австралийцы и даже создали движение «Stop phubbing», благодаря которому стало известно, что явление, которое захватило весь цивилизованный мир на уровне пользователей, получило название fabbing. По свидетельству аналитиков, явление фаббинга вытекает из целого ряда причин, в том числе психологического характера, в первую очередь - это Интернет-зависимость, и такие фобии информационной реальности, как номофобия - страх, фобия остаться без мобильного телефона или вдалеке от него и FOMO-фобия - страх пропустить что-то, а также трудности с самоконтролем, приводят к зависимости от смартфона и от сети, что, в свою очередь, ведет к фаббингу [12].

International Culture \& Technology Studies, Vol. 3, No. 1-2 
Что касается значимости упреждения его последствий, специалисты определили фаббинг как конец цивилизации. Однако эксперты обращают внимание на то, в обществе происходит постепенное осознание значимости живого общения, которое выражается в том, что, например, сегодня во многих музеях и выставочных залах Европы появился запрет на палку селфи, а в кафе и ресторанах все чаще можно встретить объявление: «Нет, у нас нет вай-фай, говорите друг с другом!», в свою очередь, большие корпорации в своих социальных проектах активно подключаются к популяризации живого общения.

В свою очередь, специалисты в качестве психологических средств защиты от проявлений интернет-зависимости предлагают, например, так называемый цифровой детокс, т.е. временный отказ от общения в сети (смартфона, планшета, компьютера) в целях концентрация внимания на реальном общении с близкими, друзьями, коллегами по работе, а также, так называемая «цифровая диета», как умение регулировать свое присутствие в сети и пользование гаджетами. В частности, известный американский телеведущий и журналист, Даниел Сиберг своей книге «Цифровая диета: как победить зависимость от гаджетов и технологий», ставшей мировым бестселлером, предлагает 4-х шаговую стратегию, которая помогает свести использование электронных устройств и технологий к разумным и комфортным для каждого пределам. По мнению Сиберга, мы растрачиваем свои ресурсы на общение с «железкой», но при этом теряем в качестве общения с живыми людьми, нам не хватаем времени на чтение настоящей литературы, на изучение реального мира, в котором мы живем [8].

Номофобия, FOMO, фаббинг, и в целом диджитал зависимость - это, прежде всего, самоконтроль и конкретные действия, которые должны базироваться, в том числе и на главном принципе этикетной коммуникации - приоритет всегда должен отдаваться живому общению.

В этой связи следует отметить, что если тема взаимодействия с гаджетами в нашей стране в настоящее время находится в состоянии осмысления, то за рубежом повседневные практики цифрового этикета, связанные с использованием гаджетов постепенно начинают оформляться в конкретные правила поведенческой культуры. Одним примеров культивации этих правил в общественном сознании являются вышедшие недавно в США книги: «Деловой этикет от Эмили Пост», авторы П. Пост, А. Пост и др. и «Не кладите смартфон на стол. Правила этикета, которые помогут вам быть на высоте», авторы - Д. Джонсон, Л. Тайлер. Каждая из этих книг, несмотря на, казалось бы, общую тематику, связанную с пропагандой хороших манер в условиях современных реалий повседневного и делового взаимодействия, вносит свой особый вклад не только в развитие правил этикетного поведения в обществе, но и в новое общее дело формирование правил нового этикета, в том числе и правил пользования гаджетами.

Таким образом, цифровая этикетная коммуникация, которая характеризуется таким важным направлением развития, как взаимодействие пользователей с гаджетами, представляет собой включенность интернет-технологий в практики повседневной жизни и деловой среды, или оффлайн / онлайн взаимодействие. Данный процесс остро нуждается в своем оформлении, т. е. в выработке основных этикетных рекомендаций такого взаимодействия с позиций специалистов, прислушивающихся в то же время и к мнению пользователей.

Однако этикетная коммуникация в цифровой среде, помимо поведения в сети и взаимодействия с гаджетами, имеет еще один важный аспект - это самопрезентации в сети на персональном и корпоративном уровнях или персональный и корпоративный брендинг, остановимся на рассмотрении этого аспекта подробнее.

\section{3. Цифровой этикет: самопрезентации в сети}

Цифровая самопрезентация - это новый вид самопрезентации в сети персонального и корпоративного уровней, которая несет в себе не только новые смыслы, отражающие специфику современной информационной цивилизации, но и становится важным инструментом конкурентоспособности и самореализации в условиях глобального рынка и цифровой экономики, поскольку в эпоху цифровых реалий в борьбу вступили уже не только корпоративные имиджи, деловые репутации и бренды компаний, но и персональные репутации и бренды сотрудников компаний [7]. 
Цифровая самопрезентация обладает всеми свойствами, характеризующими Интернеткоммуникацию в условиях нового Web 3.0 и, в частности - это функции самоконтроля и самоуправления, расширение транслирующей и интерактивной функций, а также качественно новое наполнение коммуникативной функции, связанное с акцентом нового Web на вопросах взаимодействия пользователей с новыми технологиями $[3,9]$. В свою очередь это значит, что предъявление «Я-информации» и «Мы-информации» внешнему миру в новых условиях включает в себя необходимые знания и умения, традиционно составляющие понятие «самопрезентация», а также новые, обусловленные развитием новых и новейших информационно-коммуникативных технологий. Поэтому цифровая самопрезентация представляет собой новую форму коммуникативного взаимодействия, которая может быть реализована как в онлайн, так и оффлайн / онлайн режимах. В этой связи актуализируется значение презентационного навыка на персональном и корпоративном уровнях самопрезентации.

Сегодня специалисты называют владение презентационным навыком - «ключевым навыком XXI века» [1, с. 249]. При этом следует особо подчеркнуть, что среди инструментов формирования этого важнейшего навыка новой реальности, особое место занимает этикет, в его классическом и цифровом форматах. Покажем это на примере такого вида корпоративной самопрезентации в сети, как переговоры, в частности, на примере организации и проведения конференц-колла, поскольку в настоящее время SIP-телефония стала одной из наиболее важных средств делового общения. Поэтому сначала несколько слов о SIP-телефонии.

В первую очередь следует развести понятия IP-телефония и SIP-телефония, поскольку часто эти понятия используются как синонимы, хотя таковыми они не являются. IP-телефония (Internet Protocol) - это более широкое понятие, это протокол передачи данных по сети или технология звонков и видеообщения с помощью интернета. Именно IP связал все компьютерные сети мира в Глобальную сеть Интернет. Поэтому у всех компьютеров есть свой уникальный IPадрес, который нужен для обмена данными.

SIP-телефония (Session Initiation Protocol) - является разновидностью IP-телефонии (Internet Protocol) и представляет собой только один из протоколов передачи данных, т.е. это более узкое понятие, его часто сравнивают с языком, который помогает клиентам понять друг друга и обмениваться данными без ошибок. Сегодня SIP-телефония считается самым современным видом телефонии, поскольку он основан на использовании последних достижений в области передачи данных. Новый вид взаимодействия в сети представляет собой наиболее перспективный способ развития IP-телефонии, так как позволяет привязать номер уже не к конкретному географическому месту, а к конкретному человеку, поэтому пользователь будет на связи везде, где есть доступ в интернет. При этом, SIP-протокол поддерживает передачу не только голоса, но и видеопотока и применяется для реализации множества целей, в том числе для проведении аудио- и видеосовещаний, переговоров, конференций, форумов и др. Однако, технологические характеристики нового вида взаимодействия в сети накладывают свой отпечаток не только на технологическую, но и на коммуникативную, и, в том числе, этикетную составляющую общения в процессе организации и проведения таких мероприятий. Поэтому, подчеркнем еще раз, в новых условиях речь идет о знаниях конвергентного характера, совмещающих знание этикетных правил организации и проведения мероприятий представительского уровня, проходящих в режиме реального времени, а также знание новых технологий и правил поведенческой культуры в цифровой среде, формирующихся на основе действия этих технологий.

В этом отношении очень интересным является опыт совместной деятельности интернетиздания «Медуза» и компании «Билайн» по сбору, анализу и составлению правил проведения конференц-коллов. Результатом этой совместной работы стал перечень из 13 основных этикетных рекомендаций для проведения эффективных переговоров такого формата. В качестве примера приведем некоторые из этих рекомендаций:

- подготовьтесь к звонку и узнайте побольше о своих собеседниках;

- не опаздывайте на конференц-коллы;

- если есть возможность, включите видео;

- смотрите в веб-камеру;

International Culture \& Technology Studies, Vol. 3, No. 1-2 
- не звоните прямо в пижаме из кровати;

- если вы хотите записать звонок - предупреждайте об этом всех участников;

- выключайте микрофон, если не собираетесь говорить (фоновый шум); и др. [11].

Bce предлагаемые рекомендации снабжены необходимыми комментариями и ориентированы в основном на технологические особенности таких переговоров, но именно эти особенности во многом и определяют правила Нового этикета, в рамках которого реализуются возможности нового Web 3.0. Поэтому правила делового этикета, касающиеся вопросов организации и проведения переговоров, проходящих в режиме реального времени, наложенные на технологические особенности ведения переговоров в цифровом пространстве, в частности, использования такого нового вида связи в сети как SIP-телефония, представляют собой этикетные правила проведения конференц-коллов и в целом деловых переговоров в Интернет-пространстве.

Таким образом, в рамках корпоративной самопрезентации в сети, этикетная коммуникация представляет собой знания конвергентного характера, совмещающие знание правил делового этикета, в частности, в вопросах организации и проведения мероприятий представительского уровня (деловые встречи, переговоры, конференц-колы, деловые и бизнес презентации и т.п.), проводимых в режиме реального времени, а также правил поведенческой культуры в цифровой среде, которые формируются на основании действия новых и новейших ИКТ. Поэтому, подчеркнем еще раз, в цифровом этикете ценность Другого / Других не теряет своего значения, но имеет как прямой, так и опосредованный характер, обусловленный знаниями и умениями пользователей взаимодействовать с новыми информационно-коммуникативными технологиями.

В целом, проведенный анализ показывает, что каждое из выделенных направлений общение в сети, взаимодействие пользователей с гаджетами, а также презентации в сети, имеет свою специфику и особенности. Однако, независимо от того, о каком из направлений идет речь, цифровой этикет представляет собой реализацию сущностных характеристик этикетной коммуникации в виртуальном пространстве, осуществляемых на базе новых и новейших ИКТ. Поэтому, соответственно, и дальнейшее развитие каждого из направлений связано не только с его спецификой, но и с реализацией двойной природы цифрового этикета как нового вида этикетной коммуникации в сети. В то же время, каждое направление должно стать предметом отдельного анализа, с целью формирования цифрового этикета как единой целостной нормативно-этической системы регуляции всех уровней взаимодействия, которые складываются в пространственновременном континууме современного информационного общества. Таковы роль и значение выявления методологических оснований построения данной системы.

\section{Заключение}

Цифровой этикет - это новый коммуникативный феномен новой информационной реальности, определяющий правила поведенческой культуры в виртуальном пространстве в условиях становления и развития Web третьего поколения. Поэтому при исследовании цифрового этикета необходимо исходить из его двойной природы, поскольку новый этикет отражает не только сущностные характеристики этикетной коммуникации в цифровой среде, но и специфику новых и новейших ИКТ, на базе которых он функционирует, и как следствие, представляет собой взаимосвязь и взаимодействие правил поведенческой культуры, принятых в практиках реального бытия социума и правил, основанных на технологических практиках его виртуального бытия, т.е. находится на стыке гуманитарного и технико-технологического знания, и в целом выступает как современное междисциплинарное знание, определяющее новые правила нового этикета в современных условиях. В свою очередь, междисциплинарный характер цифрового этикета требует внимания специалистов практикующихся как в области гуманитарного знания, так и знания новых и новейших ИКТ с целью оформления нового этикета в новый вид этикетной коммуникации и приобретения им своего статус-кво. 


\title{
Литература
}

[1] Андерсон K. TED TALKS. Слова меняют мир: первое официальное руководство по публичным выступлениям. Москва: Издательство «Э», 2016.

[2] Жабенко И. Цифровой барьер и глобальные информационные сети. / Коммуникативные стратегии информационного общества. Труды $1 \mathrm{X}$ международной научно-теоретической конфренции $26-27$ октября 2017 г. СПб.: Изд-во Политехн. ун-та, 2017. С. 33-37.

[3] Каган М.С. Философская теория ценности. СПб., Издательство «Петрополис», 1997.

[4] «Кодекс поведения в Интернет» // Студия IT-Labs. URL: http://it-labs.narod.ru/part10.htm\#al (дата обращения - 21.06.2018).

[5] Лукинова O. Как не бесить друг друга в Интернете. // Международный проект «Сноб». URL: https://snob.ru/entry/150669 (дата обращения: 26.02.2018).

[6] Мамина Р.И. Деловой этикет в системе имиджа: философско-культурологичский анализ. СПб. ИД: «Петрополис», 2012.232 c.

[7] Мамина Р.И. Искусство самопрезентации. СПб. ИД: «Петрополис», 2017.

[8] Сиберг Д. Цифровая диета: как победить зависимость от гаджетов и технологий. М. Альпина Паблишер, 2018. $170 \mathrm{c}$.

[9] Хайдаров К.А. Введение в Web-технологии // Bourbai Research - Частное Боровское исследовательское учреждение по внедрению новых технологий, 2015. URL: http://www.Bourabai.kz/dbt/web/evolution.htm/ (дата обращения: 26.02.2018).

[10] Хветкевич А. Говорит и показывает Интернет или Web 3.0 в действии // Инфоник - корпоративный блог и новостной портал. URL: https://info.nic.ua/articles/article-opinion/govorit-i-pokazyivaet-internet-ili-web-3$0-\mathrm{v}-\mathrm{d} /$ (дата обращения: 10.07.2018).

[11]Цифровой этикет: Как успешно провести онлайн-переговоры. Разбираемся вместе с компанией «Билайн» // Meduza Project - интернет-издание. URL: https://meduza.io/feature/2017/12/07/kak-provestiidealnyy-konferents-koll-13-pravil (дата обращения: 21.06.2018).

[12] Что такое фаббинг? // Проект «Лайфхакер». URL: https:/lifehacker.ru/2017/05/12/phubbing (дата обращения: 26.02.2018).

[13]Этикет у народов Южной Азии. СПб.: Петербургское Востоковедение, 1999.

[14]Пащенко М., Элькин А. Неоэтикет // П@Эль - портал, посвященный неоэтикету. URL: https://www.pael.pro/neoetiquetteru (дата обращения: 26.02.2018).

[15]Бибаева Д. Автопостинг vs Кросспостинг // Нетология - университет интернет-профессий. URL: https://netology.ru/blog/avtoposting-vs-krossposting (дата обращения: 10.03.2018).

[16]Попова Р. Цифровой этикет: не рассчитывайте на дисклеймер // Look at me - интернет-издание o креативных индустриях. URL: http://www.lookatme.ru/mag/how-to/etiquette/216111-etiquette-disclaimer (дата обращения: 20.03.2018).

\section{Digital etiquette: methodology issues}

\author{
R.I. Mamina
}

Saint Petersburg State Electrotechnical University "LETI", Russia

\begin{abstract}
It is shown that digital etiquette is a new type of etiquette communication, which is formed in the space of the World Global Network of the third generation - Web 3.0 and, as a consequence, operates both in online and offline/online modes. The role and importance of digital etiquette in modern realities are discussed; the main trends of its development are picked out, including direct communication in the network, interaction with gadgets, as well as self-presentation in the network. Specificity and peculiarities of each direction are discussed in the context of digital etiquette as a single integrated system. It is emphasized that a new kind of etiquette represents a modern interdisciplinary knowledge of theoretical and applied nature, which is currently in the stage of its development; therefore, it necessarily requires the attention of both humanitarians and specialists in the sphere of new and emerging information and communication technologies.
\end{abstract}

Keywords: information society, netiquette, digital etiquette, Semantic Web 3.0, nomophobia, FOMOphobia, phubbing, digital detox, digital self-presentation, SIP-telephony, business negotiations, meeting call. 


\section{References}

[1] Anderson K. TED TALKS. Slova menyayut mir: pervoe oficial'noe rukovodstvo po publichnym vystupleniyam. Moskva: Izdatel'stvo «E», 2016.

[2] Zhabenko I. Cifrovoj bar'er i global'nye informacionnye seti. / Kommunikativnye strategii informacionnogo obshchestva. Trudy 1H mezhdunarodnoj nauchno-teoreticheskoj konfrencii $26-27$ oktyabrya 2017 g. SPb.: Izd-vo Politekhn. un-ta, 2017. S. 33-37.

[3] Kagan M.S. Filosofskaya teoriya cennosti. SPb., Izdatel'stvo «Petropolis», 1997.

[4] «Kodeks povedeniya v Internet» // Studiya IT-Labs. URL: http://it-labs.narod.ru/part10.htm\#al (data obrashcheniya - 21.06.2018).

[5] Lukinova O. Kak ne besit' drug druga v Internete. // Mezhdunarodnyj proekt «Snob». URL: https://snob.ru/entry/150669 (data obrashcheniya: 26.02.2018).

[6] Mamina R.I. Delovoj etiket v sisteme imidzha: filosofsko-kul'turologichskij analiz. SPb. ID: «Petropolis», 2012. $232 \mathrm{~s}$

[7] Mamina R.I. Iskusstvo samoprezentacii. SPb. ID: «Petropolis», 2017.

[8] Siberg D. Cifrovaya dieta: kak pobedit' zavisimost' ot gadzhetov i tekhnologij. M. Al'pina Pablisher, 2018. 170 s.

[9] Hajdarov K.A. Vvedenie v Web-tekhnologii // Bourbai Research - Chastnoe Borovskoe issledovatel'skoe uchrezhdenie po vnedreniyu novyh tekhnologij, 2015. URL: http://www.Bourabai.kz/dbt/web/evolution.htm/ (data obrashcheniya: 26.02.2018).

[10] Hvetkevich A. Govorit i pokazyvaet Internet ili Web 3.0 v dejstvii // Infonik - korporativnyj blog i novostnoj portal. URL: https://info.nic.ua/articles/article-opinion/govorit-i-pokazyivaet-internet-ili-web-3-0-v-d/ (data obrashcheniya: 10.07.2018).

[11]Cifrovoj etiket: Kak uspeshno provesti onlajn-peregovory. Razbiraemsya vmeste s kompaniej «Bilajn» // Meduza Project - internet-izdanie. URL: https://meduza.io/feature/2017/12/07/kak-provesti-idealnyykonferents-koll-13-pravil (data obrashcheniya: 21.06.2018).

[12] Chto takoe fabbing? // Proekt «Lajfhaker». URL: https://lifehacker.ru/2017/05/12/phubbing (data obrashcheniya: 26.02.2018).

[13] Etiket u narodov Yuzhnoj Azii. SPb.: Peterburgskoe Vostokovedenie, 1999.

[14]Pashchenko M., El'kin A. Neoetiket // P@El' - portal, posvyashchennyj neoetiketu. URL: https://www.pael.pro/neoetiquetteru (data obrashcheniya: 26.02.2018).

[15]Bibaeva D. Avtoposting vs Krossposting // Netologiya - universitet internet-professij. URL: https://netology.ru/blog/avtoposting-vs-krossposting (data obrashcheniya: 10.03.2018).

[16] Popova R. Cifrovoj etiket: ne rasschityvajte na disklejmer // Look at me - internet-izdanie o kreativnyh industriyah. URL: http://www.lookatme.ru/mag/how-to/etiquette/216111-etiquette-disclaimer (data obrashcheniya: 20.03.2018). 